\title{
Aerosol Jet Printing of Nickel Oxide Nanoparticle Ink with Ultraviolet Radiation Curing for Thin Film Temperature Sensors
}

\author{
Yi-Tse Chang ${ }^{1,2}$, Kuan-Yi Hung ${ }^{2}$, Hong-Tsu Young ${ }^{2}$, Kuan-Ming Li ${ }^{2}$, Roland. K. Chen ${ }^{1}{ }^{*}$ \\ ${ }^{1}$ School of Mechanical and Materials Engineering Washington State University Pullman, WA, \\ 99163, United States \\ ${ }^{2}$ Department of Mechanical Engineering, National Taiwan University, Taipei, 10617, Taiwan \\ *Correspondence: roland.chen@wsu.edu
}

\begin{abstract}
In this study, ultraviolet (UV) radiation curing process and furnace curing process for curing aerosol jet printed nickel oxide $(\mathrm{NiO})$ nanoparticle thin films were investigated. $\mathrm{NiO}$ has a negative temperature coefficient and can be used to fabricate temperature sensors. Four UV power settings (for 10 minutes) and four furnace temperatures (for one hour) were used to cure the aerosol jet printed sensors. The resultant sensor resistance at $100^{\circ} \mathrm{C}$ and $180^{\circ} \mathrm{C}$ were measured, and the sensor's sensitivity was characterized by B value. Confocal microscopy was performed to characterize the sensor surface. The $60 \% \mathrm{UV}$ power setting yields the lowest resistance and the highest B value among all sensors. The analysis of variations shows that the UV power setting is not a significant factor on the resistance and $\mathrm{B}$ value, while the furnace temperature is a significant factor. This indicates that UV curing is a more robust method and does not need to be optimized to achieve good results. The UV curing process not only reduces the required curing time but also improve the performance of the temperature sensor.
\end{abstract}

Keywords: aerosol jet printing, 3D printing, thermistor, curing

\section{Introduction}

Temperature sensors are used in many research and industrial applications, such as integrated circuit chips [1], micro-resistance temperature detector arrays [2], and measuring metal cutting temperature [3]. Thermistors, made with a material that has a negative temperature coefficient (NTC), is a common type of temperature sensor. The electrical resistance of a NTC thermistor decreases non-linearly when the temperature increases [4]. NTC thermistors are mostly composed of transition metal oxides made of nickel $(\mathrm{Ni})$ and combined with manganese, cobalt, and copper [4]-[7]. Alternate materials, such as samarium (Sm) and terbium (Tb), for NTC thermistors are used in order to expand the measurable temperature range have also been reported up to $1000^{\circ} \mathrm{C}$ in comparison to the typical maxima temperature up to $500^{\circ} \mathrm{C}$ [8][9]. In addition to the measurable temperature range, sensitivity is another important indicator for the performance of a sensor. The sensitivity of a NTC sensor can be characterized using the B constant [11]. Commercial NTC thermistors usually have a $\mathrm{B}$ value above $3500 \mathrm{~K}$ [12]. The required facilities to fabricate temperature sensors using conventional processes are expensive and time consuming. These processes consist of at least four steps including raw precursor molding, pre-sintering precursor, 
sintering precursor at $1000^{\circ} \mathrm{C}$ for several hours, and thermistor packaging [10]. The sintering process is especially time consuming.

Additive manufacturing (AM) processes such as inkjet printing and screen printing have been applied to fabricate temperature sensors in order to simplify the conventional process [13]. Huang et al. used the inkjet printing process to fabricate temperature sensors using a $\mathrm{NiO}$ nanoparticlesbased ink [12]. The thermistor can operate over a wide range of temperature from 20 to $250{ }^{\circ} \mathrm{C}$ with a great sensitivity (4000K in B value). This process reduces the number of steps and material waste in comparison to conventional manufacturing processes. Aerosol jet printing (AJP) is a direct writing process and is one of the printing techniques that has been used on fabricate lines under $20 \mu \mathrm{m}$ with inks and resins [14]. AJP is capable of depositing materials on curved substrate at room temperature and atmospheric pressure [15] and can work with inks of a wide range of viscosity (1- $2500 \mathrm{cP})$ and multiple types of materials, including polymers and metals. The AJP process deposits materials in a continuous line and is different from the inkjet printing process that uses piezoelectric actuators to generate droplets in a discontinuous manner. Therefore, AJP produces both a smooth and fine line as compared to lines printed by inkjet.

The curing process is often required for 3D printing processes that use inks containing metal nanoparticles, such as silver and copper, in order to remove solvents or to sinter particles [16]. Thermal approaches, such as furnace heating, are commonly used for the curing process. The sensitivity of NTC thermistors depends on the curing time and the curing temperature. Wang et al. fabricated a thermistor on a turning insert using AJP and achieved a B value of $4310 \mathrm{~K}$ [11]. However, the fabrication process includes a one-hour furnace curing process. The optimal furnace curing temperature has not been determined. A more robust and time-efficient curing method which leads to consistent and high-performance temperature sensors is still needed. Photonic heating approaches including laser and UV heating are two alternative approaches for curing and have the potential to reduce the curing time. Metal nanoparticles show very intense surface plasmon resonance bands in UV to visible regions of the electromagnetic spectrum[17], [18]. The selective heating approach using visible light has been applied to cure or sinter metal nanoparticles with LED light (wavelength is $400 \mathrm{~nm}$ ) [19] and plasmon resonance [20]. El Kemary et al. [21] investigated the optical absorption spectra of $\mathrm{NiO}$ nanoparticles and showed that for $\mathrm{NiO}$ nanoparticles, the strongest absorption spectrum is at about $329.5 \mathrm{~nm}$ wavelength. Therefore, UV radiation could be an efficient way to sinter NiO nanoparticles. Polzinger et al. applied UV light on silver nanoparticles and found that a lower electrical resistance corresponds to the better consistency of nanoparticles [22]. Saleh et al.[16] 3D printed electronic circuitry using inks with silver nanoparticles sintered by UV radiation. Wunscher et al. suggested that UV radiation can be used as an assisted sintering approach in conjunction with other thermal treatment techniques for better efficiency [23]. They also pointed out that increasing efficiency and decreasing the costs of the post curing process is still needed to promote $3 \mathrm{D}$ printed sensors and electronic devices to an industrial scale. UV sintering offers a cost-effective approach and can be integrated with the 3D printing systems which can significantly reduce the fabrication time of multiple layers.

The goal of this study is to develop an optimized UV curing process for fabrication of thermistors using AJP. Thermistors post cured by UV will be compared with thermistors cured by furnace heating. The performance of the thermistors will be evaluated, including the consistency of particle curing to be assessed by measuring their electrical resistance and the sensitivity using the B value. 


\section{Method}

\subsection{Ink preparation}

For the thermistor, the preparation procedure and the formula of $\mathrm{NiO}$ nanoparticle ink for inkjet printing proposed by Huang et al.[12] were modified for AJP which requires an average particle size of $50 \mathrm{~nm}$. The composition of the ink includes $0.5 \mathrm{~g}$ of NiO nanoparticles (SkySpring Nanomaterials, inc., Houston, TX, USA), 2 g of propylene glycol methyl ether (PGME) and $8 \mathrm{~g}$ of deionized water. To increase the particle suspension stability, the $\mathrm{pH}$ value of $\mathrm{NiO}$ nanoparticle ink was adjusted by $\mathrm{HNO} 3$ solution and $\mathrm{NaOH}$ solution. The suggested $\mathrm{pH}$ value for AJP ink is between 3 to 5 in order to avoid particle aggregation [11]. Figure 1 shows examples of NiO nanoparticle inks printed with aggregated and non-aggregated nanoparticles. The ink mixture was then centrifuged at 3000 revolution per minute for 10 minutes and filtered with a $0.45-\mu \mathrm{m}$ syringe filter to remove any remaining large particle aggregates before used for AJP. For the conducting pad, a silver nanoparticle ink (PV Nano Cell, Migdal Haemek, Israel) was used.
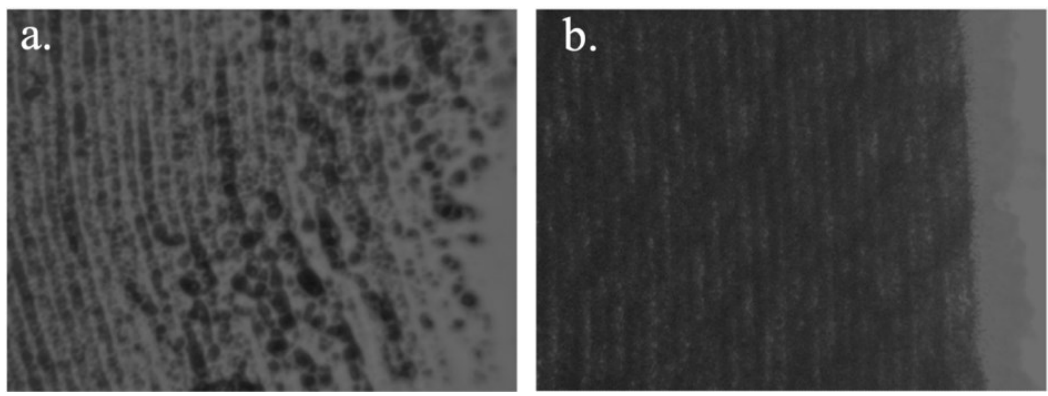

Figure 1. NiO nanoparticle ink printed by AJP: (a) aggregated particles and (b) non-aggregated particles.

\subsection{Fabrication process}

An aerosol jet printer, Optomec AJ-300 (Optomec, Albuquerque, NM, USA), was used in this study to fabricate temperature sensors, as shown in Figure 2. The nozzle, with a diameter of 150 $\mu \mathrm{m}$, was positioned 1 to $5 \mathrm{~mm}$ above the substrate. The ink was aerosolized with either the pneumatic or ultrasonic atomizer depending on the ink viscosity. The ultrasonic atomizer (Figure $2 \mathrm{~b}$ ) is for low-viscosity inks (1-10 cP) and the pneumatic atomizer (Figure $2 \mathrm{c}$ ) is for high-viscosity inks or resin $(10-2500 \mathrm{cP})$. The silver ink $(26 \mathrm{cP})$ was atomized by the pneumatic atomizer and the $\mathrm{NiO}$ ink $(1.52 \mathrm{cP})$ was atomized by the ultrasonic atomizer. To install thermistor on any shape of surface, the sensor was printed on a thermal resistant tape, Kapton ${ }^{\circledR}\left(\left(\right.\right.$ DuPont $^{\mathrm{TM}}$, Inc., Wilmington, DE, USA) which is a flexible substrate. Figure 3 illustrates the fabrication process. In Step 1, a pair of conductive pads consisting of three layers $(7 \mu \mathrm{m})$ of silver ink was printed on the thermal resistant tape as electrodes. These were cured by a furnace at $180^{\circ} \mathrm{C}$ for 30 minutes. In Step 2, five layers $\mathrm{NiO}$ ink were printed on top of the electrode. In Step 4, the printed sensors were cured by either UV radiation (OmniCure S2000 Spot UV Curing System, Excelitas, Waltham, MA USA) using different power settings for 10 minutes or furnace heating (Neycraft Vulcan 3-550, Dentsply, York, PA, USA) at different temperatures for one hour. 

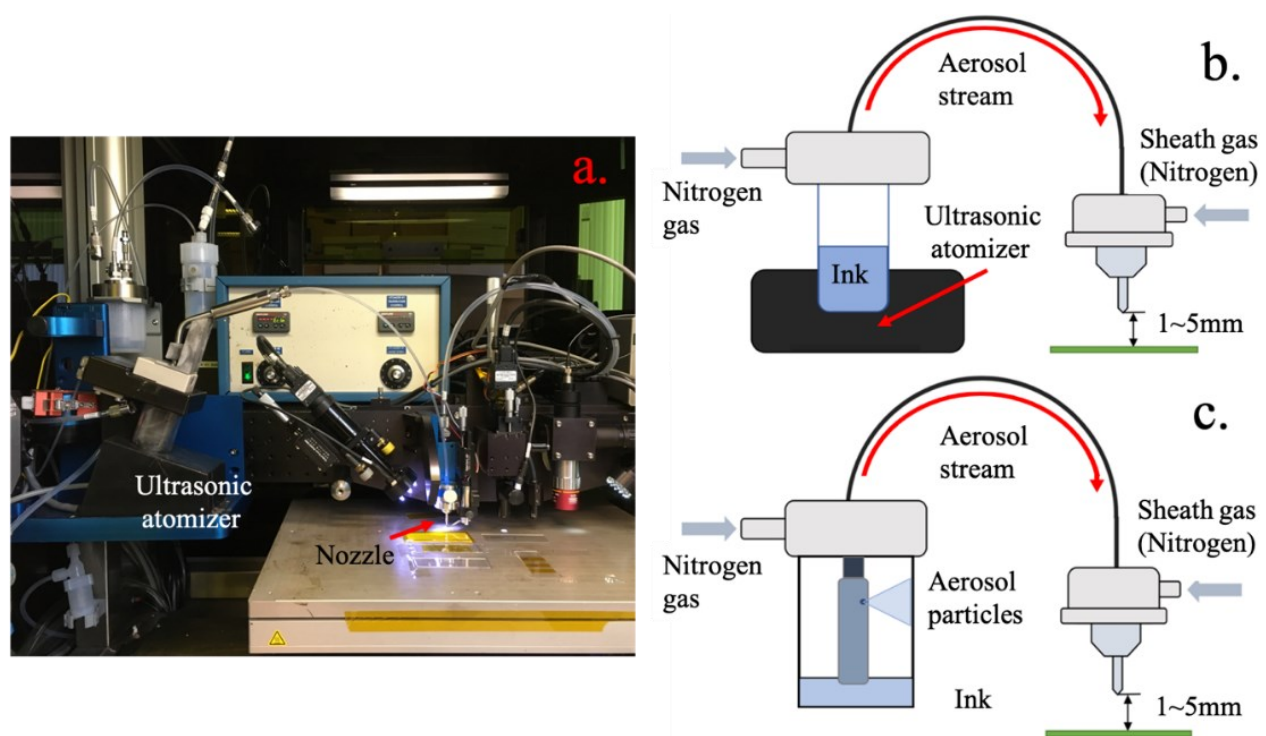

Figure 2. AJP fabrication setup: (a) overview, (b) ultrasonic atomizer, and (c) pneumatic atomizer.

a.
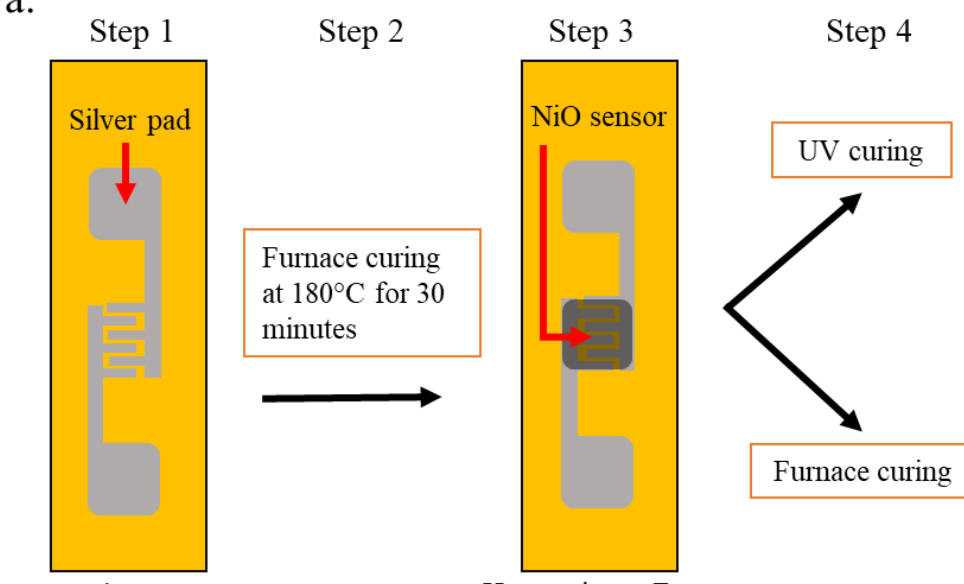

Heat resistant Tape

Heat resistant Tape

b.

$\mathrm{NiO}$ thin film

Silver interdigital electrode

Heat resistant Tape

Figure 3. Fabrication process of the temperature sensor: (a) flow chart and (b) sideview of the sensor.

\subsection{Experimental Design}

To optimize and compare the performance of UV curing and furnace curing, different UV power settings and furnace temperatures were used. These temperature settings are summarized in Table 1. The maximum power output of UV light is $30 \mathrm{~W} / \mathrm{cm}^{2}$, which can be adjusted by changing the output percentage. For UV curing, the power settings were $60 \%, 65 \%, 70 \%$ and $75 \%$ with a fixed 10 -minute curing time. The range of UV power settings was selected based on preliminary studies which showed deformed tape when the power is higher than $75 \%$. For furnace curing, the 
temperature settings were $200^{\circ} \mathrm{C}, 240^{\circ} \mathrm{C}, 260^{\circ} \mathrm{C}$ and $280^{\circ} \mathrm{C}$ with a fixed one-hour curing time. The minimal curing temperature of $200^{\circ} \mathrm{C}$ was suggested by Huang et al. [12]. The tape also deformed when exposed to temperature over $280^{\circ} \mathrm{C}$ in the furnace. Therefore, the temperature range was selected to be $200^{\circ} \mathrm{C}$ to $280^{\circ} \mathrm{C}$. For repeatability, there are three sensors were fabricated in each setting.

Table 1. UV curing and furnace curing experiments setting.

\begin{tabular}{|l|l|l|l|l|}
\hline Curing method & Setting \\
\hline UV curing & $60 \%$ & $65 \%$ & $70 \%$ & $75 \%$ \\
\hline Furnace curing & $200^{\circ} \mathrm{C}$ & $240^{\circ} \mathrm{C}$ & $260^{\circ} \mathrm{C}$ & $280^{\circ} \mathrm{C}$ \\
\hline
\end{tabular}

\subsection{Sensor characterization}

Figure 4 shows the experimental setup for sensor characterization. The sensors were placed on a heat plate alongside with a calibrated reference thermometer (ThermoWorks, American Fork, UT, US). The heat plate was used to raise the temperature to $100^{\circ} \mathrm{C}(373.15 \mathrm{~K})$ and $180^{\circ} \mathrm{C}$ $(453.15 \mathrm{~K})$. When the temperature became stable, the resistance of the thermistor was measured using a digital multimeter, HP 34401 A 6.5 (HP, Palo Alto, CA, US). Each sensor and temperature setting were tested three times to ensure repeatability. The B value represents the sensitivity of an NTC sensor and was used to characterize all printed temperature sensors. The higher the B constant, the better the sensitivity. The B value (K) can be calculated using the Arrhenius equation (Eq. 1) [11]

$$
B \text { value }=\frac{\operatorname{In}\left(R_{1}\right)-\operatorname{In}\left(R_{2}\right)}{\frac{1}{T 1}-\frac{1}{T 2}}
$$

where $R_{1}$ and $R_{2}$ represent the resistance measured at temperature T1 $(373.15 \mathrm{~K})$ and T2 $(453.15 \mathrm{~K})$, respectively.

The microstructure of the deposited $\mathrm{NiO}$ thin films was examined with confocal microscopy, Keysight VK-X210 (Keyence Corporation, Osaka, Japan) with 20 times and 150 times magnification. ANOVA was performed using Excel (Microsoft, Redmond, WA, US) to determine the statistical difference $(p$ value $<0.05$ ) between two curing methods. 

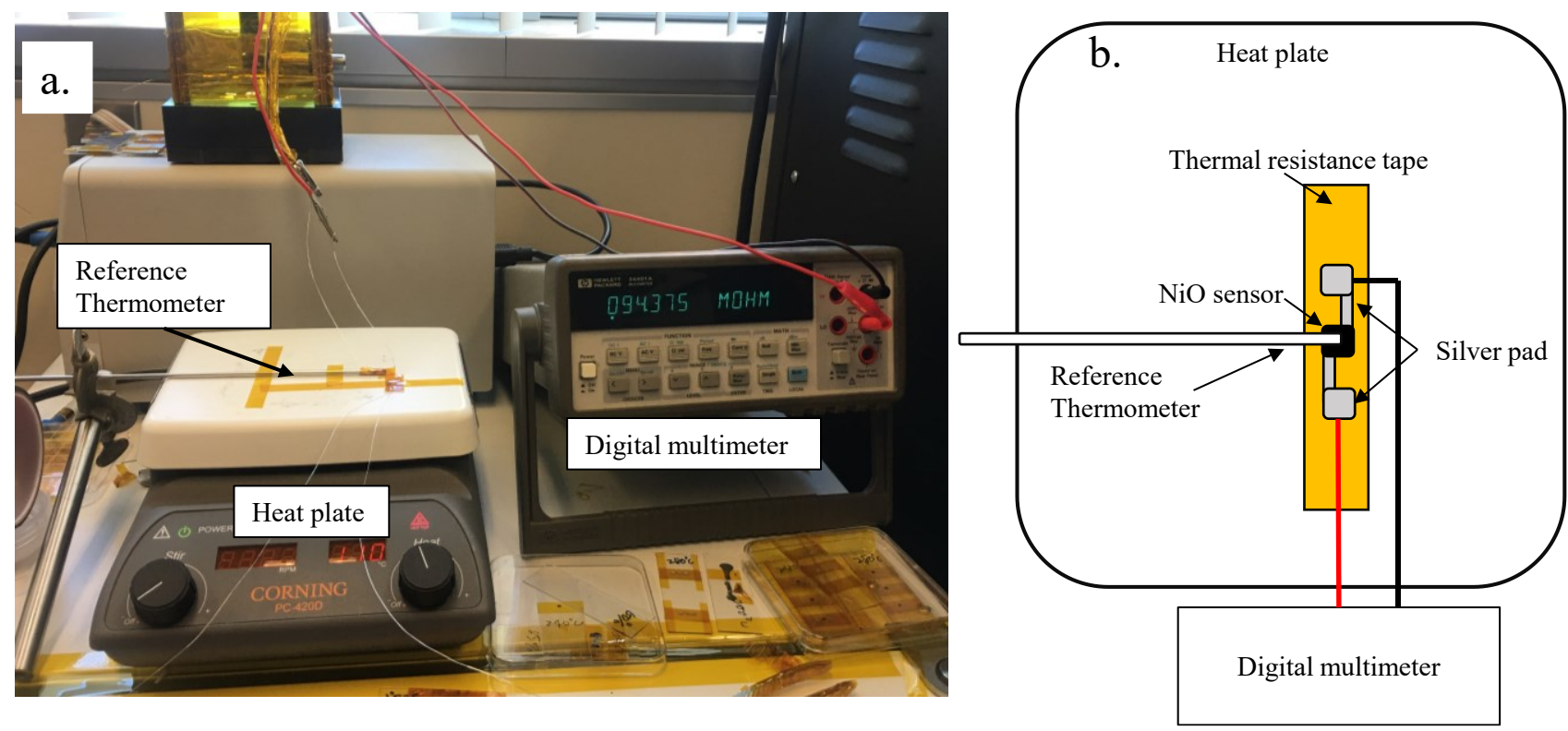

Figure 4 Experimental setup for sensor characterization: (a) overview and (b) schematic diagram of resistance measurement setup.

\section{Results and Discussion}

Figures $5(\mathrm{a})$ and (b) show the resistances of sensors cured by UV radiation at $100^{\circ} \mathrm{C}$ and $180^{\circ} \mathrm{C}$, respectively. The sensor cured by $60 \% \mathrm{UV}$ power has the lowest resistances for both $100^{\circ} \mathrm{C}$ and $180^{\circ} \mathrm{C}$. A lower resistance indicates better consistency of sintered particles [22]. The resistance values slightly increase as the UV power increases. Figure 6(a) and (b) show the resistances of sensors, measured at $100^{\circ} \mathrm{C}$ and $180^{\circ} \mathrm{C}$, respectively, cured by the furnace using different temperatures for one hour. The sensor cured by $260^{\circ} \mathrm{C}$ shows the lowest resistance for both $100^{\circ} \mathrm{C}$ and $180^{\circ} \mathrm{C}$.

Figure 7 shows the B values of sensors cured by both UV and furnace. Every sensor has a B value above $4000 \mathrm{~K}$ which is higher than $3500 \mathrm{~K}$, the typical requirement for commercial thermistors [12]. The sensors cured by $60 \%$ UV power have the highest B value, $5301.65 \mathrm{~K}$, among all sensors. The highest $\mathrm{B}$ value among sensors cured by the furnace is $5231.68 \mathrm{~K}$ from sensors cured at $260^{\circ} \mathrm{C}$. The average B value for all UV power settings and furnace temperatures is $5079.19 \mathrm{~K}$ and 4618.6 $\mathrm{K}$, respectively. The ANOVA shows that there is a significant difference in $\mathrm{B}$ value between the two curing methods ( $p$-value $<0.05$ ). Also, there is no significant difference in $\mathrm{B}$ value among different UV power settings while there the difference in B value is significant among different furnace curing temperature. This indicates that UV curing is a more robust curing process than furnace curing, as the B value, a performance measure of temperature sensors, is less sensitive to the UV power setting. When using furnace curing, the temperature needs to be optimized to achieve the best sensitivity. The B values achieved in this study are all higher than $4310 \mathrm{~K}$, the B value reported by a previous study that used AJP to fabricate temperature sensors [11]. This shows an improvement of the sensor's sensitivity by optimizing the curing process. Moreover, the UV curing process only takes 10 minutes. In comparison to the one-hour furnace curing time, the total fabrication time can be reduced significantly. 


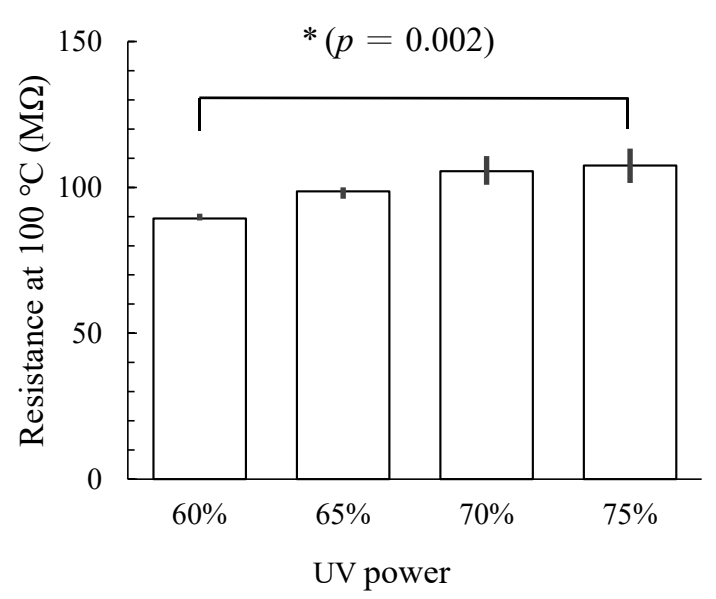

(a)

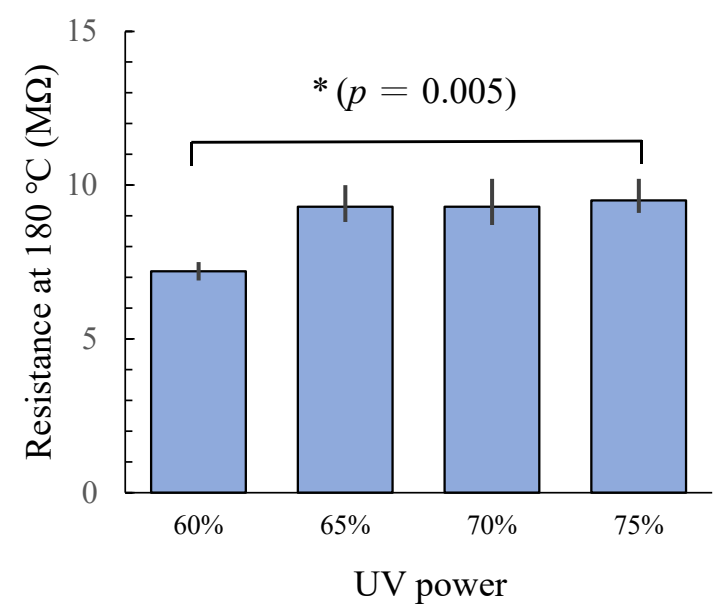

(b)

Figure 5. Resistances of fabricated temperature sensors using UV curing at (a) $100^{\circ} \mathrm{C}$ and (b) $180^{\circ} \mathrm{C}$.

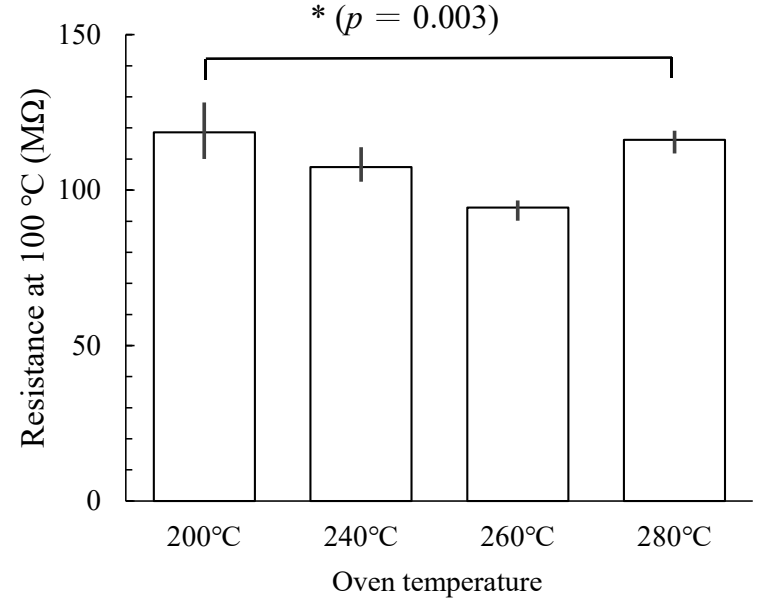

(a)

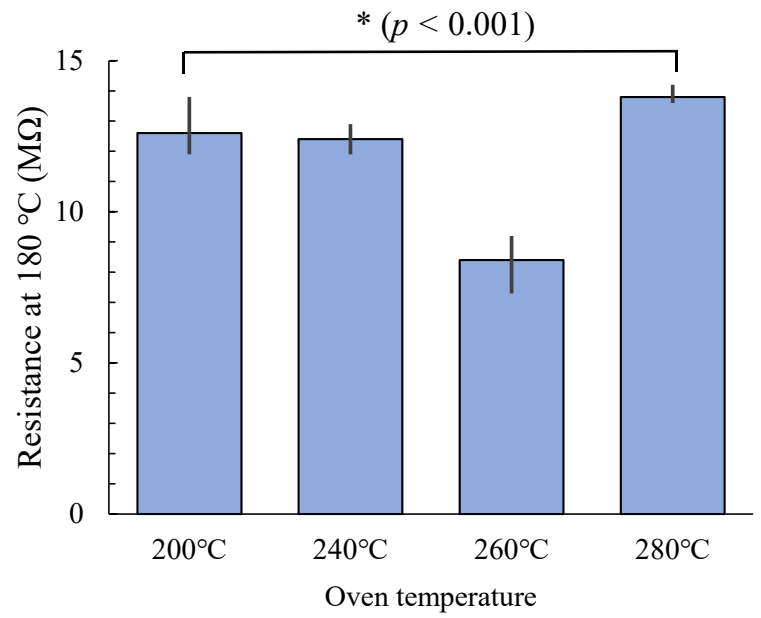

(b)

Figure 6. Resistances of fabricated sensors cured by furnace at (a) $100^{\circ} \mathrm{C}$ and (b) $180^{\circ} \mathrm{C}$. 


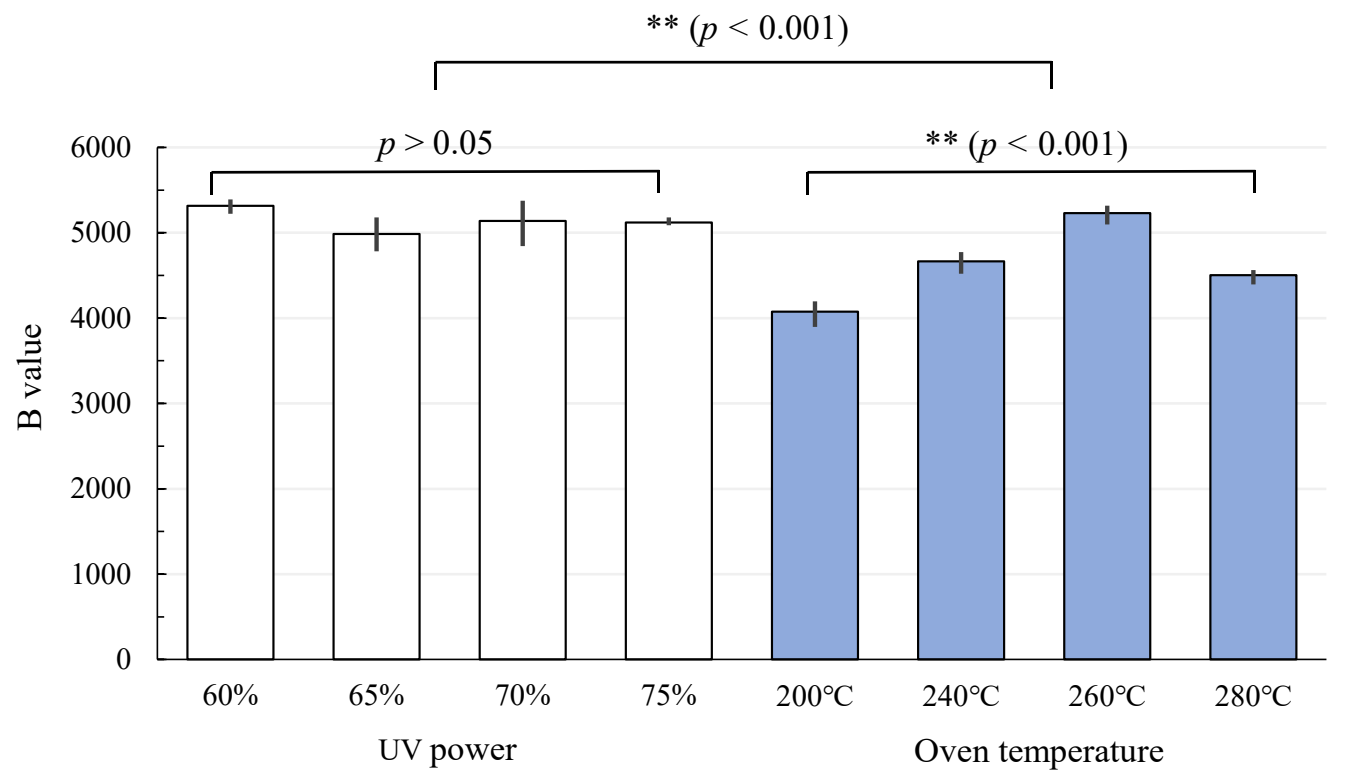

Figure 7. B value of all experiments.

Figures $8(\mathrm{a})$ - (d) show the confocal microscopy images $(150 \mathrm{x})$ of surfaces from sensors with the highest $\left(60 \%\right.$ and $\left.260^{\circ} \mathrm{C}\right)$ and lowest $\mathrm{B}$ values $\left(75 \%\right.$ and $\left.280^{\circ} \mathrm{C}\right)$ for both curing methods. In Figures 8(a) and (c), $\mathrm{NiO}$ nanoparticles closely form a consistently thin film, and these two sensors correspond to the lowest resistance and the highest $\mathrm{B}$ value, cured by $60 \% \mathrm{UV}$ and $260^{\circ} \mathrm{C}$, respectively. Figure $8(\mathrm{~b})$ shows the sensor surface cured by $75 \%$ of UV power. There are a few visible cracks, indicated by arrows. The cracks can contribute to the increase in resistance and inconsistency. In Figure 8(d), some aggregated particles can be observed. However, even with the existence of those minor defects, the sensors still exhibit good sensitivity. Figures $8(\mathrm{e})-(\mathrm{h})$ show the color maps of height variations on the sensor surfaces. In all color maps, several NiO particles on the surface are clearly visible as high spots. Figure $8(\mathrm{~g})$ shows the most even surface and Figure 8 (f) shows the most variation in heights. Table 2 summarizes the resistances (at $100^{\circ} \mathrm{C}$ and $180^{\circ} \mathrm{C}$ ), $\mathrm{B}$ values, and surface roughness $(\mathrm{Ra})$ of the sensors shown in Figure 8 . The sensor cured by furnace at $260^{\circ} \mathrm{C}$ has the lowest $\mathrm{Ra}$. Sensors cured by $60 \% \mathrm{UV}$ power and $260^{\circ} \mathrm{C}$ have lower Ra than those cured by $75 \%$ UV power and $280^{\circ} \mathrm{C}$. A lower Ra, indicating a smoother surface, can lead to a lower resistance and better consistency. Although furnace curing shows a lower overall Ra value, owing to a gentle curing process, the curing time is much longer than UV curing. There are some limitations in Ra measurement. The silver paths are under the thin $\mathrm{NiO}$ film and the deformation of the substrate can cause variations on the surface. Therefore, instead of covering the whole sensor area for Ra measurement, areas between silver lines were chosen for Ra measurement to minimize the effect of substrate deformation. 

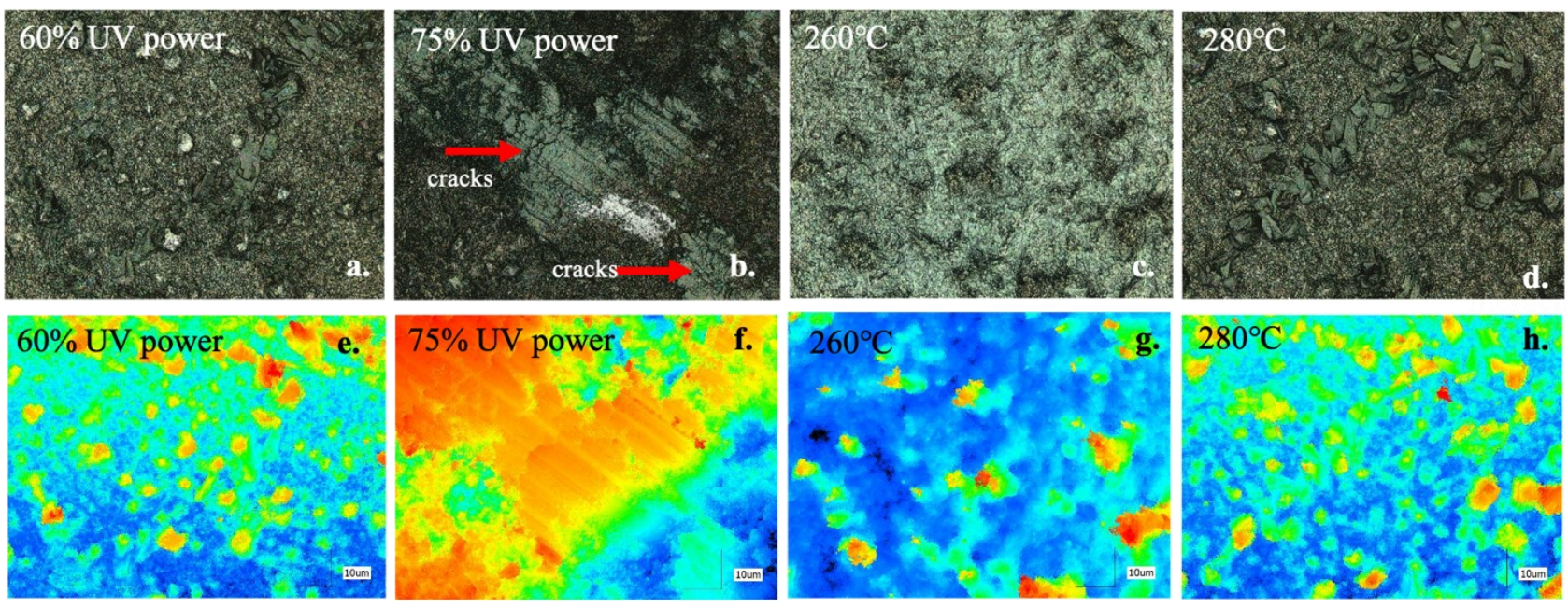

Figure 8. Confocal microscopy image (a) - (d) and height color map (e) - (h) of the best and worst cases of sensors cured by UV and furnace process.

Table 2. Summary of resistance, B value and surface roughness for the best and worst cases of each curing method.

\begin{tabular}{|l|l|l|l|l|}
\hline Curing method & $\begin{array}{l}\text { Resistance at } 100^{\circ} \mathrm{C} \\
(\mathrm{M} \Omega)\end{array}$ & $\begin{array}{l}\text { Resistance at } 180^{\circ} \mathrm{C} \\
(\mathrm{M} \Omega)\end{array}$ & B value & $\begin{array}{l}\text { Roughness } \\
(\mathrm{Ra})\end{array}$ \\
\hline UV radiation $(60 \%)$ & 88.8 & 7.23 & $5301.7 \mathrm{~K}$ & $1.87 \mu \mathrm{m}$ \\
\hline UV radiation $(75 \%)$ & 107.5 & 9.5 & $5007.5 \mathrm{~K}$ & $2.44 \mu \mathrm{m}$ \\
\hline Furnace $\left(260^{\circ} \mathrm{C}\right)$ & 106.8 & 8.83 & $5231.7 \mathrm{~K}$ & $1.63 \mu \mathrm{m}$ \\
\hline Furnace $\left(280^{\circ} \mathrm{C}\right)$ & 118.5 & 13.8 & $4536.2 \mathrm{~K}$ & $2.15 \mu \mathrm{m}$ \\
\hline
\end{tabular}

Figures 9 and 10 show the confocal microscopy images of a corner of the sensors cured by UV and furnace, respectively. In Figure 9(a) and Figure 10(a), the black areas are the printed $\mathrm{NiO}$ sensor and the grey strips are the silver conductive lines. Figure 9(b) and Figure 10(b) show the color height map of Figure 9(a) and Figure 10(a), respectively, in which red corresponds to the high and blue corresponds to the low points. The profile of sensor and silver path can be observed easily. Figures 11 shows the extracted height profiles along the numbered areas in Figure 9(a) and Figure 10(a). The average heights in the numbered areas are labeled in Figure 11. The thickness of the sensor can be estimated by subtracting the height of substrate from the height of the $\mathrm{NiO}$ thin film area. For example, as shown in Figure 11(b), the height in (4) is $116.73 \mu \mathrm{m}$ (substrate) and the height in (6) is $121.47 \mu \mathrm{m}$ (NiO thin film), leaving a difference of $4.74 \mu \mathrm{m}$ which is the thickness of thin film. However, in the case of Figure 11(a), the substate is not flat, due to the deformation of the heat resistant tape, and thus it is difficult to measure the thickness of the $\mathrm{NiO}$ thin film. This can also be observed in Figure 9(b) which shows a higher top right corner and a lower bottom left corner in the thin film. This observation indicates that furnace curing is a gentler curing process which leads to less deformation of the substrate, although the process takes a longer time. A closer examination of the substrate deformation when using UV curing can be conducted further in the future. 


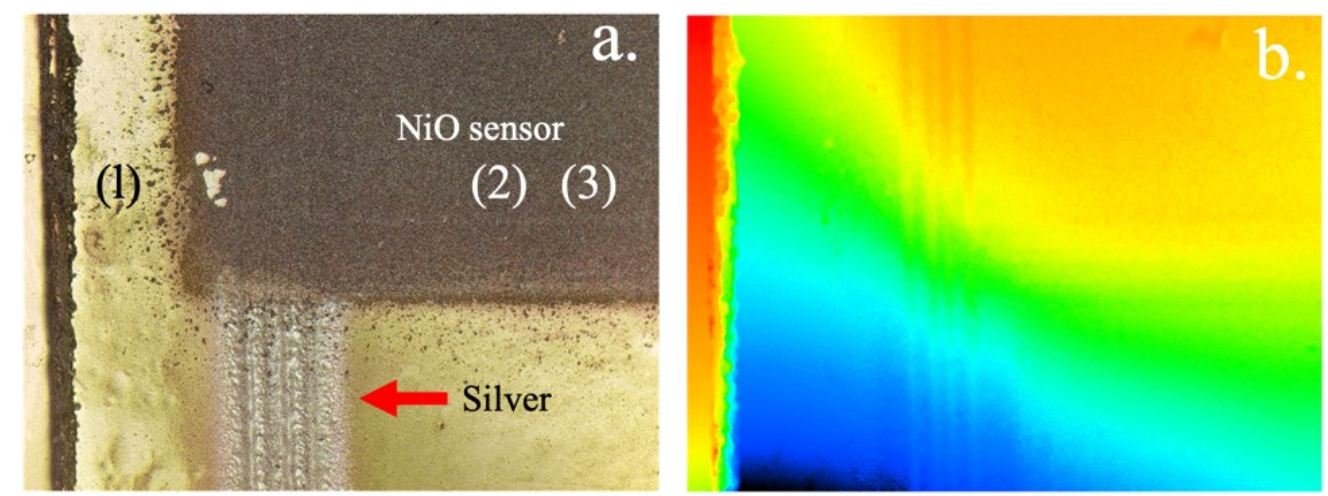

Figure 8. Confocal microscopy image of sensor surface thickness cured by $60 \%$ power output UV irradiation.
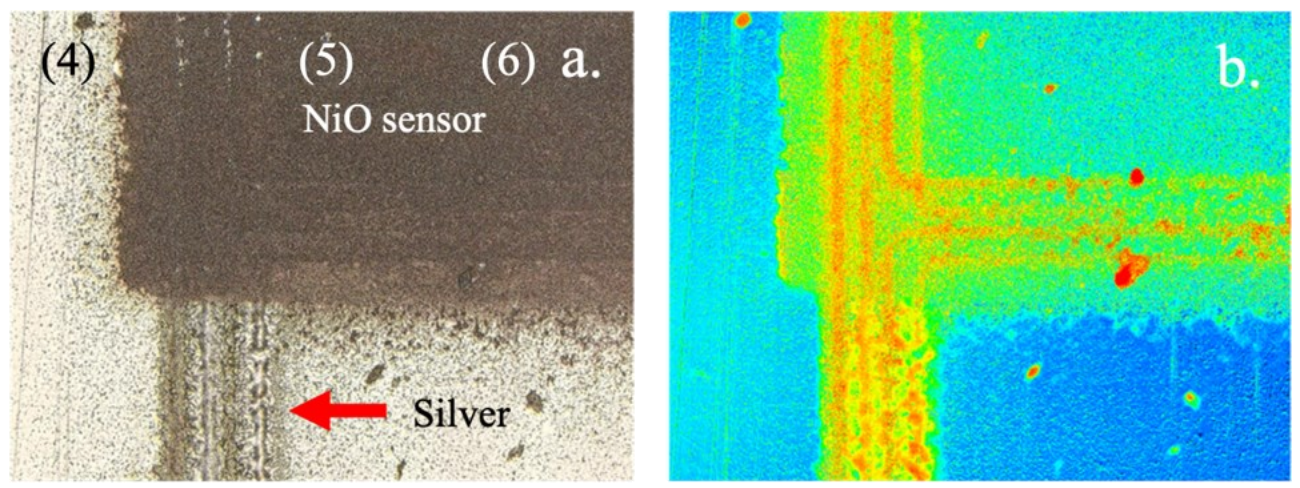

Figure 9. Confocal microscopy image of sensor surface thickness cured by furnace at $260^{\circ} \mathrm{C}$.

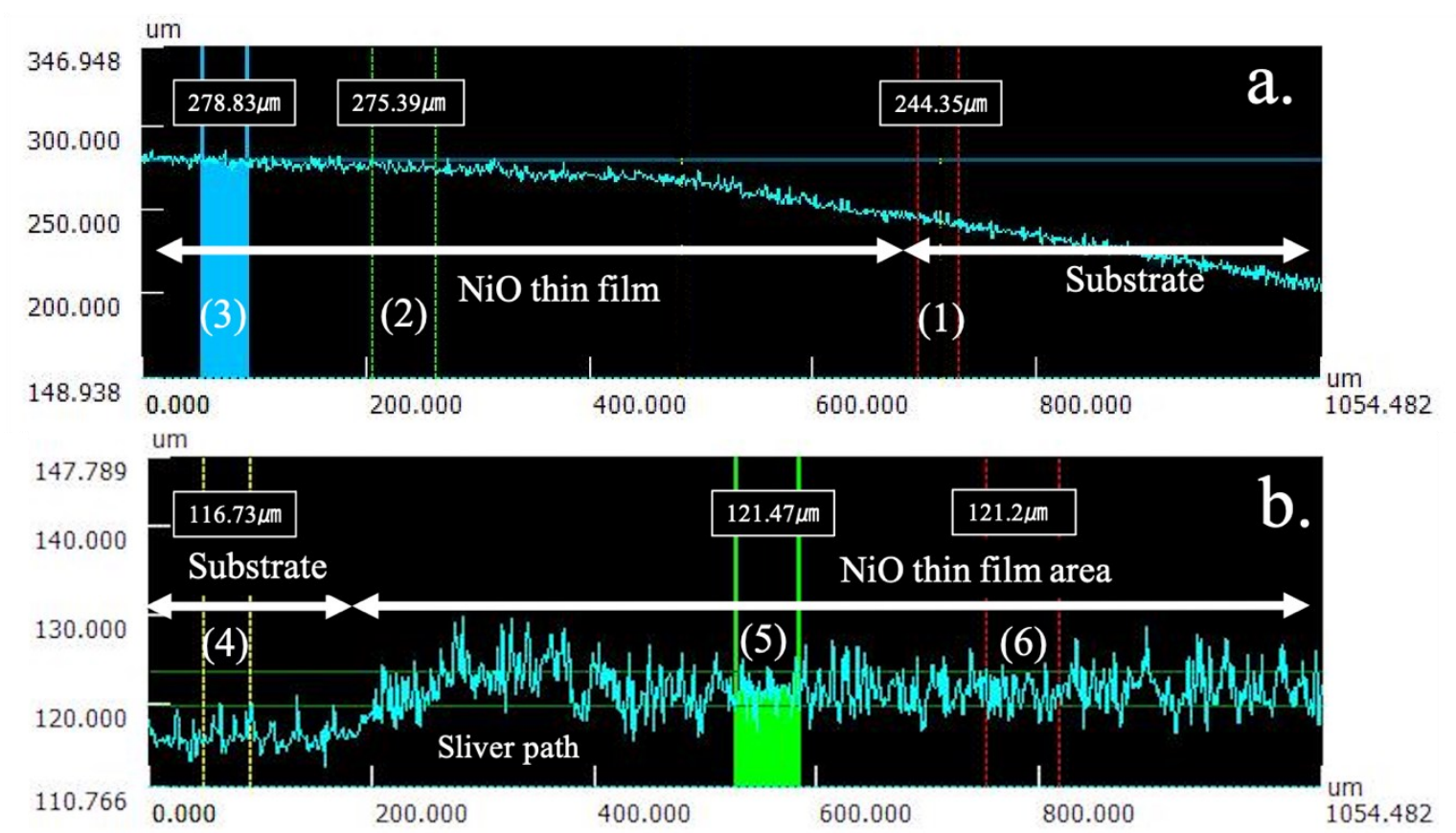

Figure 10. Surface heigh profiles of (a) UV cured sensor (Figure 8(a)) and (b) furnace cured sensor (Figure 9(a)). 


\section{Conclusions}

This study explores an efficient UV-radiation curing method for AJP of NiO nanoparticles ink for fabrication of thin film temperature sensors. The UV curing process significantly reduces the curing time from one hour to 10 minutes making the fabrication process much more efficient. The $60 \%$ UV power setting shows the best results among all sensors. $260^{\circ} \mathrm{C}$ furnace shows the best results among the four furnace curing temperatures. On average, the UV cured sensors also show significantly higher B values, an indicator of the sensor's sensitivity, than those underwent furnace curing. While the furnace curing temperature has a significant effect on the B value, the UV power setting does not have a significant effect. This indicates that UV curing is a more robust method for curing and does not need to be optimized as much as the temperature for furnace curing. The confocal microscopy results show that over curing may cause micro cracks on the sensor surface, thus reducing the consistency and sensitivity. Future work can include using even lower radiation output to minimize the deformation of the substrate or a higher radiation output with a shorter curing time.

\section{References}

[1] H. Liu, W. Sun, A. Xiang, T. Shi, Q. Chen, and S. Xu, "Towards on-chip time-resolved thermal mapping with micro-/nanosensor arrays," Nanoscale Res Lett, vol. 7, no. 1, p. 484, 2012, doi: 10.1186/1556-276X-7-484.

[2] I. Y. Han and S. J. Kim, "Diode temperature sensor array for measuring micro-scale surface temperatures with high resolution," Sensors and Actuators A: Physical, vol. 141, no. 1, pp. 52-58, Jan. 2008, doi: 10.1016/j.sna.2007.07.020.

[3] K.-M. Li and S. Y. Liang, "Modeling of Cutting Temperature in Near Dry Machining," Journal of Manufacturing Science and Engineering, vol. 128, no. 2, pp. 416-424, May 2006, doi: 10.1115/1.2162907.

[4] P. Ouyang, H. Zhang, Y. Zhang, J. Wang, and Z. Li, "Zr-substituted SnO2-based NTC thermistors with wide application temperature range and high property stability," J Mater Sci: Mater Electron, vol. 26, no. 8, pp. 6163-6169, Aug. 2015, doi: 10.1007/s10854-0153197-7.

[5] A. Feteira, "Negative Temperature Coefficient Resistance (NTCR) Ceramic Thermistors: An Industrial Perspective," Journal of the American Ceramic Society, vol. 92, no. 5, pp. 967-983, May 2009, doi: 10.1111/j.1551-2916.2009.02990.x.

[6] J. A. Becker, C. B. Green, and G. L. Pearson, "Properties and Uses of ThermistorsThermally Sensitive Resistors," p. 43.

[7] S. D. Wood, B. W. Mangum, J. J. Filliben, and S. B. Tillett, "An investigation of the stability of thermistors," J. RES. NATL. BUR. STAN., vol. 83, no. 3, p. 247, May 1978, doi: 10.6028/jres.083.015.

[8] C. C. Wang, S. A. Akbar, W. Chen, and J. R. Schorr, "High-temperature thermistors based on yttria and calcium zirconate," Sensors and Actuators A: Physical, vol. 58, no. 3, pp. 237-243, Mar. 1997, doi: 10.1016/S0924-4247(97)01394-0.

[9] D. Houivet, J. Bernard, and J.-M. Haussonne, "High temperature NTC ceramic resistors (ambient-1000 'C)," Journal of the European Ceramic Society, vol. 24, no. 6, pp. 12371241, Jan. 2004, doi: 10.1016/S0955-2219(03)00376-5. 
[10] R. K. Kamat and G. M. Naik, "Thermistors - in search of new applications, manufacturers cultivate advanced NTC techniques," Sensor Review, vol. 22, no. 4, pp. 334-340, Dec. 2002, doi: 10.1108/02602280210444654.

[11] Chia Wang, Guan-Yi Hong, Kuan-Ming Li, and Hong-Tsu Young, “A Miniaturized Nickel Oxide Thermistor via Aerosol Jet Technology," Sensors, vol. 17, no. 11, p. 2602, Nov. 2017, doi: 10.3390/s17112602.

[12] C.-C. Huang, Z.-K. Kao, and Y.-C. Liao, "Flexible Miniaturized Nickel Oxide Thermistor Arrays via Inkjet Printing Technology," ACS Appl. Mater. Interfaces, vol. 5, no. 24, pp. 12954-12959, Dec. 2013, doi: 10.1021/am404872j.

[13] Q. Huang and Y. Zhu, "Printing Conductive Nanomaterials for Flexible and Stretchable Electronics: A Review of Materials, Processes, and Applications," Adv. Mater. Technol., vol. 4, no. 5, p. 1800546, May 2019, doi: 10.1002/admt.201800546.

[14] A. Mette, P. L. Richter, M. Hörteis, and S. W. Glunz, "Metal aerosol jet printing for solar cell metallization,” Prog. Photovolt: Res. Appl., vol. 15, no. 7, pp. 621-627, Nov. 2007, doi: 10.1002/pip.759.

[15] R. (Ross) Salary, J. P. Lombardi, M. S. Tootooni, R. Donovan, P. K. Rao, and M. D. Poliks, "In Situ Sensor-Based Monitoring and Computational Fluid Dynamics (CFD) Modeling of Aerosol Jet Printing (AJP) Process," in Volume 2: Materials; Biomanufacturing;

Properties, Applications and Systems; Sustainable Manufacturing, Blacksburg, Virginia, USA, Jun. 2016, p. V002T04A049. doi: 10.1115/MSEC2016-8535.

[16] E. Saleh et al., "3D Inkjet Printing of Electronics Using UV Conversion," Adv. Mater. Technol., vol. 2, no. 10, p. 1700134, Oct. 2017, doi: 10.1002/admt.201700134.

[17] K. L. Kelly, E. Coronado, L. L. Zhao, and G. C. Schatz, "The Optical Properties of Metal Nanoparticles: The Influence of Size, Shape, and Dielectric Environment," J. Phys. Chem. $B$, vol. 107, no. 3, pp. 668-677, Jan. 2003, doi: 10.1021/jp026731y.

[18] J. Z. Zhang and C. Noguez, "Plasmonic Optical Properties and Applications of Metal Nanostructures," Plasmonics, vol. 3, no. 4, pp. 127-150, Dec. 2008, doi: 10.1007/s11468008-9066-y.

[19] Y. Li, T. Verbiest, R. Strobbe, and I. F. J. Vankelecom, "Silver nanoparticles as localized 'nano-heaters' under LED light irradiation to improve membrane performance," J. Mater. Chem. A, vol. 2, no. 9, p. 3182, 2014, doi: 10.1039/c3ta14406b.

[20] A. O. Govorov and H. H. Richardson, "Generating heat with metal nanoparticles," Nano Today, vol. 2, no. 1, pp. 30-38, Feb. 2007, doi: 10.1016/S1748-0132(07)70017-8.

[21] M. El-Kemary, N. Nagy, and I. El-Mehasseb, "Nickel oxide nanoparticles: Synthesis and spectral studies of interactions with glucose," Materials Science in Semiconductor Processing, vol. 16, no. 6, pp. 1747-1752, Dec. 2013, doi: 10.1016/j.mssp.2013.05.018.

[22] B. Polzinger et al., "UV-sintering of inkjet-printed conductive silver tracks," in 2011 11th IEEE International Conference on Nanotechnology, Portland, OR, USA, Aug. 2011, pp. 201-204. doi: 10.1109/NANO.2011.6144541.

[23] S. Wünscher, R. Abbel, J. Perelaer, and U. S. Schubert, "Progress of alternative sintering approaches of inkjet-printed metal inks and their application for manufacturing of flexible electronic devices," J. Mater. Chem. C, vol. 2, no. 48, pp. 10232-10261, Sep. 2014, doi: 10.1039/C4TC01820F. 